This report was written by Professor Margaret Turner-Warwick, Dr. J. C. Batten, the co-ordinators, and the M.R.C. participants.

\section{References}

Altounyan, R. E. C. (1967). Acta Allergologica, 22, 487. Altounyan, R. E. C., and Howell, J. B. L. (1969). Respiration, 26, Suppl. No. 131.

Blacknell, M. I., and Jones, R. S. (1970). In Disodium Cromoglycate in Allergic Airways Disease, ed, J. Pepys and A. W. Frankland, p. 63. London, Butterworths.

Bruce, R. A., and Hansell, J. L. (1968). Practitioner, 201, 915.

Campbell, A. H., and Tandon, M. K. (1969). Medical fournal of Australia,

Chen, Joyce L., Moore, N., Norman, P. S., and Van Metre, T. E., jun. (1969). Fournal of Allergy, 43, 89.

Cox, J. S. G. (1967). Nature, 216, 1328.

Davies, S. E. (1968). British Medical fournal, 3, 593

Davies, S. E. (1970). In Disodium Cromoglycate in Allergic Airways Disease, ed. J. Pepys and A. W. Frankland, p. 55. London, Butterworths.

Goose, J., and Blair, A. M. J. N. (1969). Immunology, 16, 749.

Grant, I.'W. B., Channell, S., and Drever, J. C. (1967). Lancet, 2, 673.

Howell, J. B. L., and Altounyan, R. E. C. (1967). Lancet, 2, 539.
Kennedy, M. C. S. (1967). Lancet, 2, 838.

Lane, D. J. (1969). British Medical fournal, 4, 710 Lopez, M., Lowell, F. C., and Franklin, W. (1969). Fournal of Allergy, 44, 118

Minette, A. (1970). In Disodium Cromoglycate in Allergic Airways Disease, ed. J. Pepys and A. W. Frankland, p. 45. London, Butterworths.

Moran, F., Bankier, J. D. H., and Boyd, G. (1968). Lancet, 2, 137.

Morrison-Smith, J., and Devey, G. F. (1968). British Medical fournal, 2, 340. Muittari, A., and Kreus, K. E. (1969). British Medical fournal, 4, 170.

Munro Ford, R. (1969). Medical fournal of Australia, 2, 537.

Orie, N. G. M., et al. (1970). In Disodium Cromoglycate in Allergic Airways Disease, ed. J. Pepys and A. W. Frankland, p. 33. London,

Orr, T. S. C., and Cox, J. S. G. (1969). Nature, 223, 197.

Pepys, J., Hargreave, F. E., Chan, M., and McCarthy, D. S. (1968). Lancet, 2, 134.

Robertson, D. G., Epstein, S. W., and Warrell, D. A. (1969). British Medical Fournal, 1, 552

Silverman, M. (1972). Unpublished.

Silverman, M., Connolly, Nicola M., Balfour-Lynn. L., and Godfrey, S. (1972). British Medical fournal, 3, 378.

Ward, F. G., Gomes, S., and McNeill, R. S. (1969). British Medical fournal, $3,176$.

Williams, M. H., and Kane, C. (1969). Fournal of the American Medical Association, 209, 1881.

\title{
Changes in Lung Capillary Permeability in Renal Failure
}

\author{
W. A. CROSBIE, S. SNOWDEN, V. PARSONS
}

They were all within $2 \mathrm{~kg}$ of their normal dialysing weight, British Medical Fournal, 1972, 4, 388-390

\section{Summary}

Excess fluid in the lung can be quantified in chronic dialysis patients by using the double indicator dilution technique. The lung capillaries show an increased permeability to sodium when these patents develop pulmonary oedema.

\section{Introduction}

Pulmonary oedema is a common complication in patients with renal disease. Increased capillary pressure from a failing left ventricle, increased capillary flow due to the high cardiac output associated with anaemia, and a minor reduction in the plasma osmotic pressure secondary to low albumin concentration have been suggested as the main factors causing outflow of fluid from the capillaries into the extravascular lung tissue (Rendich et al., 1941; Alwall et al., 1953). Changes in the permeability of lung capillaries could also produce a similar effect. Thus far no quantitative means of measuring such a change in renal patients has been reported. We have applied the multiple indicator dilution technique to this problem and the results form the substance of this paper.

\section{Patients and Methods}

All the patients studied were members of a regular haemodialysis programme centred in Dulwich Hospital. The measurements were made with the subject propped up in bed. For the first study 27 patients were divided into three groups according to their clinical and radiological states. The lung water was measured independently, and became known only after this classification had been made.

Group 1.- "Normals." There were 12 patients in this group and all were regarded as free of excess fluid in their lungs.

King's College Hospital, London S.E.5

W. A. CROSBIE, M.B., M.R.C.P., Lecturer in Medicine, Chest Unit S. SNOWDEN, M.B., Medical Assistant

V. PARSONS, D.M., F.R.C.P., Consultant Physician, Renal Unit. there was no adventitious sounds in the chest, and chest radiographs showed no evidence of venous congestion or interstitial or alveolar oedema.

Groups 2.- "Overloads." There were seven patients in this group. They were at least $5 \mathrm{~kg}$ above their normal dialysing weight. They all had noticed increased breathlessness on exertion, and crepitations were audible on auscultation. Chest radiographs showed distended upper lobe veins, hilar accentuation with loss of outline of vessels, and lymphatic lines were present in two patients.

Group 3.--"Pulmonary oedema." There were eight patients in this group. All were breathless at rest, many crepitations were present in the chest, and radiographs showed varying degrees of opacification of the lung fields associated with pulmonary oedema. The clinical condition of these patients required urgent therapy to control their pulmonary symptoms.

An intravenous infusion drip was linked to the venous end of a Scribner shunt. A $1-\mathrm{ml}$ bolus containing $2.5 \mu \mathrm{Ci}$ of ${ }^{125} \mathrm{I}-$ labelled human serum albumin (RISA), $2.5 \mu \mathrm{Ci}$ of ${ }^{24} \mathrm{Na}$, and $150 \mu \mathrm{Ci}$ of tritiated water $\left(3 \mathrm{H}_{2} \mathrm{O}^{+}\right)$was injected into the venous line while the infusion flowed maximally. Thirty $1-\mathrm{ml}$ samples of blood were collected in 30 seconds from the arterial line using an automated fraction collector and pump (Crosbie and Wyatt, 1971). The amount of labelled albumin, tritiated water, and ${ }^{24} \mathrm{Na}$ recovered in each sample was measured. The ${ }^{24} \mathrm{Na}+$ count rate was measured within two hours of collection using a gamma spectrometer and well counter. The radioactivity of the ${ }^{125} \mathrm{I}$ albumin was counted three weeks later in an automated well counter when the radioactivity due to the ${ }^{24} \mathrm{Na}$ had decayed. In both instances the sample was counted sufficiently long to give a total count of the modal value, a value at least five times that of background. Standards were prepared by serial dilutions of the injectate and measured in a manner identical to that of the samples. The tritium $(3 \mathrm{H}+)$ was measured by liquid scintillation counting of the beta activity: $0.5 \mathrm{ml}$ of the blood collected in each sample was added to $4.5 \mathrm{ml}$ of absolute alcohol and left for three weeks in a refrigerator; $1 \mathrm{ml}$ of the supernatant was then added to $10 \mathrm{ml}$ of scintillation fluid (P.P.O. $4 \mathrm{~g}$, Dm-P.O.P.O.P. $0.2 \mathrm{~g}$, naphthalene $60.0 \mathrm{~g}$, dioxan 1 1.) and counted in a Tri-carb Packard automated scintillation counter. Again, serial dilutions of the injectate were treated in a similar manner to provide standards. 
The amount of each indicator recovered in each sample was then expressed as a fraction of the amount injected. Curves of the recovery concentration/amount injected against time were then constructed for each indicator. The appropriate correction values for recirculation were obtained by extrapolating the logarithmic function of the downslope of the curve. From this data the flow (Q) through the lungs, the mean transit time of each indicator $\left(\hat{t}_{x}\right)$, and the volume of distribution of the ${ }^{24} \mathrm{Na}^{+}$and tritiated water were calculated by using the methods described by Chinard (1966). The volume of distribution of the ${ }^{24} \mathrm{Na}^{+}$and $3 \mathrm{H}_{2} \mathrm{O}+$ is calculated from the product of the flow and the difference in the mean transit time of the ${ }^{125} \mathrm{I}$ albumin from each of these indications. Typical curves for the three indicators when the lung capillary permeability is normal and when it has become abnormal are shown in Fig. 1. In the normal state the ${ }^{125} \mathrm{I}$ albumin and ${ }^{24} \mathrm{Na}^{+}$curves are close together and very alike in shape. Hence there is only a small difference in their mean transit time. It is thought that normally very little sodium leaves the blood during one transit through the lung capillary bed.

When lung capillary permeability becomes abnormal (Fig. 1) the ${ }^{24} \mathrm{Na}$ curve leaves the ${ }^{125} \mathrm{I}$ albumin curve and approaches the tritiated water curve. Hence the mean transit time of

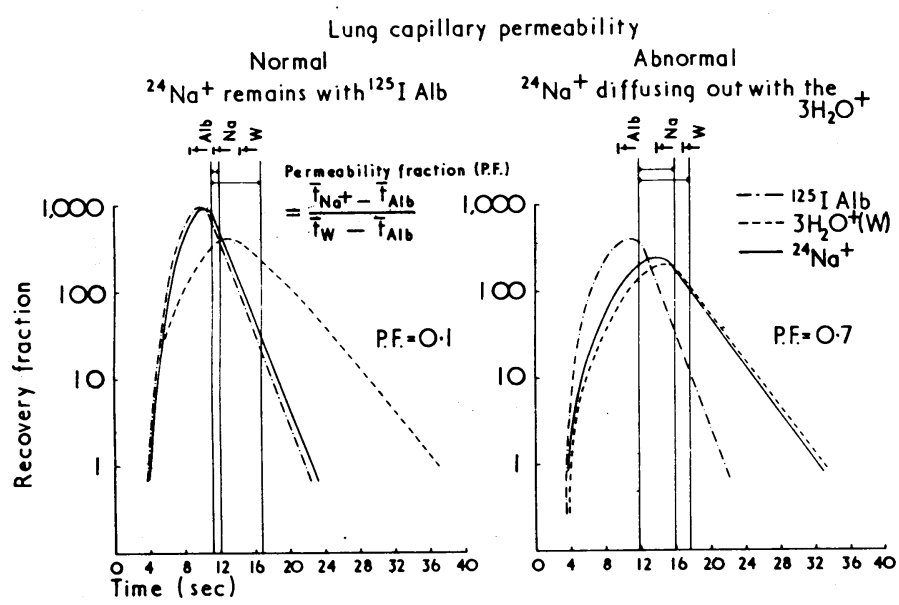

FIG. 1-Multiple indicator dilution curves obtained by using three indicators ( ${ }^{125}$ I albumin, tritiated water, and $\mathrm{Na}^{24+}$ ) when the lungs are normal and when they are oedematous.

the ${ }^{24} \mathrm{Na}$ moves further away from the mean transit time of the albumin. The sodium is now occupying a larger volume than the albumin during one transit of the lungs. To quantify the permeability charcteristics of lung capillaries we have expressed the difference in the mean transit time of the ${ }^{24} \mathrm{Na}^{+}$ and ${ }^{125} I$ albumin $\left(t_{\mathrm{Na}}-\bar{t}_{\mathrm{ALB}}\right)$ as a fraction of the difference in the mean transit time of the tritiated water and the labelled albumin $\left(\bar{t}_{W}-\bar{t}_{A L B}\right)$ and called this the permeability fraction (P.F.).

Normally, P.F. $\frac{\bar{t}_{\text {Na }}-\bar{t}_{\text {ALB }}}{\bar{t}_{w}-\bar{t}_{\text {ALB }}}$ is about $0 \cdot 1$

and becomes close to unity when the sodium and water curves approximate, at which time the sodium and the water would be occupying almost identical volumes during one transit of the lungs. Since neither of these volumes is available to the labelled albumin we must regard them as extravascular. It cannot be assumed that the sodium and water volumes are identical or occupy any particular anatomical compartment.

\section{Results}

The association between the three groups and the pulmonary extravascular water space is shown in Fig. 2. There is a highly significant difference $(P>0.01)$ between each group as defined. Hence the correlation between clinical and radiological estimation and the double indicator dilution technique for measuring the amount of water present in the lungs is good. When chronic dialysis patients retain excess body fluid there is a concomitant increase in the fluid in the lungs. When clinical pulmonary oedema develops the pulmonary extravascular water volume may be increased three to four times. The relation between the pulmonary extravascular water space and the changes in the permeability of the lung capillaries for ${ }^{24} \mathrm{Na}^{+}$in another group of 12 renal patients is shown in

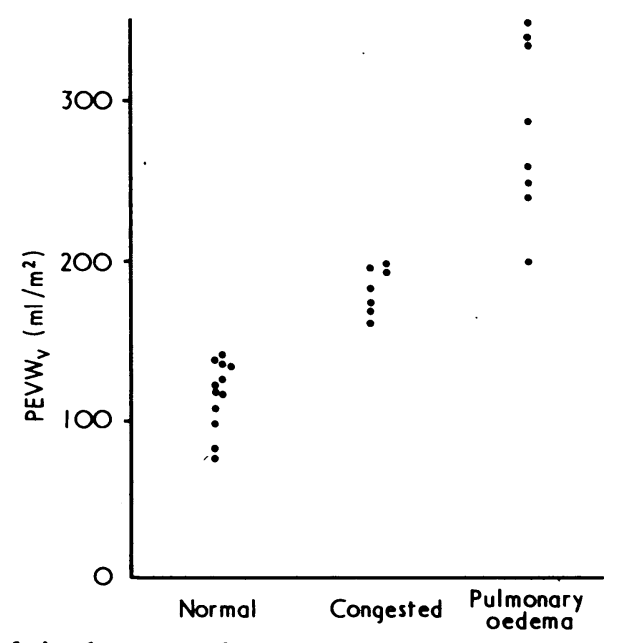

FIG. 2-Relation between pulmonary extravascular water volume (PEVW and the clinical state of three groups of chronic dialysis patients. There is statistically significant difference at the $1 \%$ level $(P>0.01)$ between each group.

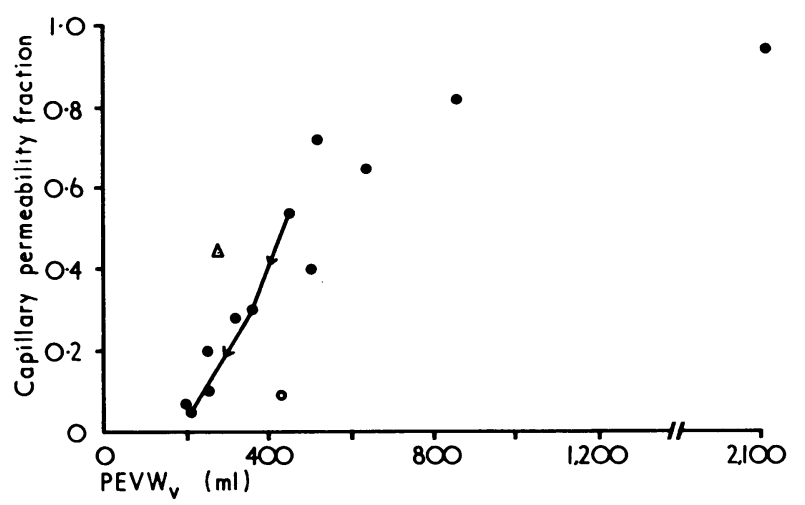

FIG. 3-Relation between the pulmonary extravascular water volume (PEVWV) and the capillary permeability fraction in a group of 12 renal patients. $=$ Patients with chronic glomerulonephritis. Arrowed line = Changes in one patient as he recovered from pulmonary oedema Patient with diabetic nephropathy. $\mathrm{O}=$ Patient with Goodpasture's syndrome.

Fig. 3. The normal pulmonary extravascular water volume of about $200 \mathrm{ml}$ and capillary permeability factor of about 0.1 is close to the axis. As the pulmonary extravascular water volume increases the capillary permeability factor also increases. The relation appears to be hyperbolic rather than linear. When the lung water space reaches about $800 \mathrm{ml}$ and the capillary permeability fraction 0.8 the curve levels out. It is apparent that a maximal transfer rate must be reached since it would be very unlikely for ${ }^{24} \mathrm{Na}$ to diffuse through capillary walls faster than water. Ten of the 12 patients were in renal failure due to chronic glomerulonephritis (Fig. 3). The serial change in one patient as he recovered from pulmonary oedema, and a patient who was a long-standing diabetic with diabetic nephropathy are also represented. The latter patient appeared to show a greater tendency to leak sodium than water compared to the other subjects. Results of a patient who was known to have Goodpasture's syndrome are also shown. Hence there is a fair correlation between the development of excess fluid in the extravascular lung tissue and an increased permeability of capillary walls for sodium in renal patients. 


\section{Discussion}

The permeability of lung capillaries for sodium and water changes when pulmonary oedema develops in renal failure. The present study shows that the extravascular water space in the lung may increase tenfold when pulmonary oedema is present. The reverse process occurs when the patient recovers and the oedema disappears. Crosbie et al. (1971) showed that the resting pulmonary extravascular water volume increased by only about $40 \%$ when normal people were subjected to hard exertion or acute hypoxia. This effect can be explained by the opening up of previously closed capillaries at the top of the lung when the overall lung perfusion increased, and hence more water-containing tissue is "seen" by the indicators.

There has been doubt that the double indicator dilution technique can measure water which has extruded into the alveoli. The magnitude of the volumes measured in group 3 patients and the patient with a volume of 2 litres in Fig. 3 would imply that water in the flooded alveoli was also being measured. The interstitial tissue of the lung appears incapable of containing all this excess fluid, hence some of the water in the flooded alveoli must also be measured. If this fluid was water alone then large forces would be necessary to drive the water across intact membranes against the plasma solute osmotic pressure. If the normal semi-permeable nature of the capillary endothelium is impaired then water and sodium will pass through these membranes more easily. The chemical potential of the water will have been significantly reduced. Sodium, being the most plentiful ion of the intravascular and extravascular fluid, will have the greatest influence on fluid exchange in the lung in these circumstances. In normal lungs of dogs and man the sodium ion remains in the vascular compartment during one transit of the lungs and Fig. 2 confirms this finding. As the lungs become progressively oedematous the sodium ion moves out with the water into the extravascular space. Since sodium is normally present in the extravascular fluid in the lung it must cross capillary walls. Under normal conditions the sodium flux into the tissues is low but when water transport is abnormally increased the rate of movement of sodium through the lung capillary walls must also be increased in renal oedema.

For a long time clinicians have suspected that the pulmonary oedema seen in association with renal disease is not adequately explained by changes in the hydrostatic and osmotic forces in the lung capillary bed. Cardiac catheter studies have shown that the capillary pressure and the osmotic pressure may both be normal when pulmonary oedema was present (Gibson, 1966; Todesco et al., 1970). A change in the permeability of the capillary wall would provide an alternative explanation. Many biological substances are known to alter the permeability of systemic capillaries. Histamine, bradykinin, 5-hydroxytryptamine, and complement fragment 3 have been shown to produce this effect. Evidence of changes occurring in the normal function of biological membranes in uraemia is now being reported from various investigators working in different dicciplines. Smith (1972) has shown that the $\mathrm{Na}^{+}$concentration inside human red blood cells is kept constant by the activity of the sodium pump. Welt (1969) reported that in some uraemic patients there is a defect in the sodium efflux from the red blood cells and that the rate constant of sodium pump $I$ is diminished. Hence a change in the distribution of intracellular and extracellular sodium concentration could well be present. Why this abnormality develops in some uraemic subjects may be explained by the results obtained from animal experiments.

Fritz and Levine (1951) showed that adrenocortical hor$\mathrm{m}^{\sim}$ nes were necessary for small blood vessels to respond optimally to pressor agents. Giese (1964) reported that an increased vascular permeability was seen in rats when renin and angiotensin were infused together. They attributed this state to the raised blood pressure which was produced by these hormones. Cuthbert et al. (1966) after their experiments suggested that the increased permeability was due to a direct effect of these agents on the vessel walls. Further investigations in this field have now been reported by Pessina and Peart (1972). They have studied the functional and morphological changes induced by the infusion of renin and antiotensin II into the normal and adrenalectomized rat. They showed how the infusion of these two hormones altered capillary permeability. The haemodynamic changes which were necessary for this effect required adequate adrenocortical function. No prominent change on the structure of the capillary wall was seen on electronmicroscopical examination of kidney tissue although a striking increase on the number of tracer substance particles was noted in the endothelial cells and basement membrane.

As an alternative explanation of our findings, it has been suggested that the movement of sodium out of the blood is dependent on the volume of fluid available in the lung tissue. Numerically our data would not be consistent with this hypothesis. Reference to Fig. 3 shows that the change in capillary permeability fraction and volume of extravascular lung water is not a simple linear function. The relation is hyperbolic and requires about $800 \mathrm{ml}$ of fluid to be present in the lung extravascular tissue before sodium and water move out from the lung capillaries at the same rate. Further investigation into the morphological changes in the lungs when this amount of fluid is present may show an anatomical explanation of these findings in the renal subject. It could be that the lungs must have flooded alveoli present before this occurs.

We have no measurement of the renin level in the present patients to support the humeral hypothesis, but some indirect evidence is available. Two patients in group 3 had severe hypertension and would most likely have had increased levels of circulatory renin. Both required bilateral nephrectomy to control their blood pressure and neither had recurrence of their pulmonary complications. A closer look at the association of lung water and the renin-angiotensin axis appears to be indicated.

Nevertheless, the results obtained in the laboratory by the experimental physiologist are consistent with the suspicions of the clinician. When uraemic patients develop pulmonary oedema we may well be observing changes occurring across biological membranes in the body. These changes may be due to the release of vasoactive hormones from the kidneys, the effects being mediated by corticosteroids released from the adrenal gland.

We express our appreciation to Dr. P. Hugh-Jones for the facilities and encouragement he provided enabling us to complete these studies. We also wish to thank Mr. Len Smith and Miss Margaret Rusbridge for their skilful technical help for the preparation of the illustrations, and to Miss Mary Howell for typing the manuscript.

\section{References}

Allwall, N., Lunderquist, A., and Olsson, O. (1953). Acta Medica Scandinavica, 146, 157 .

Chinard, F. P. (1966). Advances in Respiratory Physiology, chap. 4. London, Edward Arnold.

Crosbie, W. A., Clarke, M. B., Kidner, P. H., and Hugh-Jones, P. (1971). Central Hemodynamics and Gas Exchange, Ch. 21. Torino, Italy, Minerva Medica.

Crosbie, W. A., and Wyatt, G. (1971). Medical and Biological Engineering, 9, 725.

Cuthbert, M. F., Asscher, A. W., and Jones, J. H. (1966). Clinical Science, 31, 325 .

Fritz, I., and Levine, R. (1951). American fournal of Physiology, 165, 456.

Gibson, D. G. (1966). Lancet, 2, 1217

Giese, J. (1964). Acta Pathologica et Microbiologica Scandinavica, 62, 497. Pessina, A. C., and Peart, W. S. (1972). Proceedings of the Royal Society of London, 180, 73.

Rendich, R. A., Levy, A. H., and Cove, A. M. (1941). American fournal of Roentgenology, Radium Therapy and Nuclear Medicine, 46, 802.

Smith, E. K. M. (1972). Clinical Science, 42, 447.

Todesco, S., Borsatti, A., Maschio, G., Antonello, A., and Favaro, S. (1970). Bollettino della Societa Italiana di Biologia Sperimentale, 47, 113.

Welt, L. G. (1969). Nephron, 6, 406. 